\title{
ASPECTOS GERAIS DA \\ ATUAÇÃO DO PODER \\ JUDICIÁRIO BRASILEIRO \\ NO PROCESSO POLÍTICO
}

\section{Manoel Gonçalves Ferreira Filho}

Professor catedrático aposentado da Universidade de São Paulo.

Palestra proferida em 14/fev/2008 inaugurando o semestre letivo da FA7.

\section{INTRODUÇÃo}

O Poder Judiciário exerce, no Brasil, um amplo controle sobre a atividade política, quer no que tange ao processo eleitoral e partidário, quer no que concerne ao exercício da função governamental. Acumula as funções tradicionais de dirimir os litígios entre particulares e de sancionar penalmente a conduta destes com a de acompanhar a vida dos partidos, promover as eleições, fiscalizar a constitucionalidade, a legalidade e apreciar o próprio mérito de atos governamentais. Na verdade, o Judiciário brasileiro desempenha as funções que, noutros Estados, são exercidas pela Justiça comum, pela Justiça constitucional e pelo contencioso administrativo.

Tal quadro não é uma inovação da Constituição vigente. Desde a primeira Constituição republicana (1891), ele já era incumbido de exercer o controle de constitucionalidade e da correção dos atos governamentais irregulares. Desde 1932 - portanto, antes da segunda Constituição republicana (1934) passou a controlar o processo eleitoral e partidário. Destarte, a referida acumulação já está presente nas Leis Magnas de 1946 e de 1967, não se falando da Carta de 1937 que não teve efetividade.

Entretanto, sob a Constituição em vigor, o fenômeno se intensificou, seja em razão das novidades e características desta, que refletem a tendência mundial à judicialização da política, seja em decorrência de uma nova concepção, e por que não dizê-lo de uma nova atitude dos magistrados.

Neste trabalho, visa-se a desenhar, em traços largos, o panorama do controle jurisdicional da atividade política, segundo a letra e a prática do direito brasileiro na atualidade. Far-se-á isto num enfoque preferencialmente dinâmico, abordando de início o processo político propriamente dito, ou seja, o processo eleitoral e partidário; depois, o processo governamental, aqui compreendido o crivo sobre atos políticos, como as leis, e sobre os atos administrativos. 


\section{CONTROLE DO PROCESSO ELEITORAL E PARTIDÁRIO}

2. Um dos ramos do Poder Judiciário, no Brasil, é a Justiça Eleitoral (CF art. 92, V). Surgiu ela em 1932, com a missão de gerir o processo eleitoral, desde o arrolamento dos eleitores até a promulgação dos resultados eleitorais, com a diplomação dos eleitos, bem como todo o contencioso que decorra desse processo. Igualmente, está na sua competência desde a origem a supervisão do quadro partidário.

Este duplo papel de controle do processo eleitoral e de controle dos partidos consolidou-se com a Constituição de 1946, foi mantido pela de 1967 e está na Constituição em vigor.

3. No que concerne aos partidos, tem ela um controle sobre a organização e o funcionamento dos partidos.

Hoje, os partidos são associações, cuja instituição é livre e ganham personalidade nos termos da lei civil. Entretanto, precisam obter o registro dos estatutos no Tribunal Superior Eleitoral, a fim de gozarem das prerrogativas de partido. Ou seja, as de apresentar candidatos, usufruir de tempo gratuito nos meios audiovisuais de comunicação, participar dos recursos do fundo partidário, etc.

4. Este registro é dependente de uma exigência programática. Tem o partido de respeitar como princípios "a soberania nacional, o regime democrático, o pluripartidarismo,(e) os direitos fundamentais da pessoa humana". Tal condicionamento procede da Constituição de 1946. Esta, preocupada com a defesa da democracia contra a ameaça totalitária, proibiu o partido que, por seu "programa ou ação" contrariasse "o regime democrático, baseado na pluralidade dos partidos e na garantia dos direitos fundamentais do homem" (C 1946, art. 141, $\S 13$, combinado com art. 119, I). ${ }^{1}$ Disto resulta evidentemente a possibilidade da cassação do registro do partido que infringir os princípios mencionados.

5. Ademais, a Justiça Eleitoral tem amplo poder fiscalizatório sobre os partidos. Não só pode apreciar a regularidade de suas convenções e atos de decisão, como, por expressa disposição constitucional, tem o poder de examinar suas prestações de contas (CF art. 17, III).

6. É a Justiça Eleitoral também que aprecia a inscrição dos candidatos pelos partidos. Nisto, ela examina não somente o preenchimento pelos mesmos

\footnotetext{
${ }^{1}$ Em aplicação disto, foi cassado em 1947 o registro do Partido Comunista.
} 
das condições positivas de elegibilidade o gozo dos direitos políticos mas igualmente as eventual ocorrência de inelegibilidades. Estas, que não são poucas, visam essencialmente a impedir candidaturas que possam beneficiar-se de abuso de poder, econômico ou advindo de cargos públicos.

Note-se que a Constituição vigente prevê uma ação de impugnação de mandato (CF art. 14, § 11). Por meio desta, pode ser cassado o mandato do eleito por abuso de poder, seja econômico (inclusive despesas acima do teto), seja da máquina administrativa, no curso da campanha.

7. Relativamente ao processo eleitoral propriamente dito, a Justiça Eleitoral não só arrola os eleitores, toma os votos e os apura, como já se salientou, mas exerce um poder de polícia quanto ao desenrolar da campanha eleitoral. Age então como o árbitro de uma competição.

No exercício dele, pode proibir veiculações, que entender caluniosas ou infamantes, ou retirar do responsável tempo no horário gratuito do rádio ou da televisão, conferindo o direito de resposta ao atingido. Tem isto grande importância, porque, nas eleições nacionais e estaduais, bem como nas municipais nos grandes centros, a propaganda eleitoral é essencialmente feita por esses meios de comunicação. Para tanto, o tempo é repartido entre os partidos, por critérios definidos na legislação, de modo que a sanção irá restringir o período conferido ao infrator, diminuindo-lhe a oportunidade de difundir suas idéias e avalizar seus candidatos.

8. Desdobramento recente veio incrementar o controle jurisdicional sobre as relações entre o partido e os que elegeu.

Com efeito, há poucos meses atrás o mais alto tribunal eleitoral, o Tribunal Superior Eleitoral enfrentou essa delicada questão. Ou seja, a questão da fidelidade e da disciplina partidárias. Estas, aliás, são mencionadas no art. $17, \S 1^{\circ}$ da Constituição, como devendo fazer parte dos estatutos partidários.

Entendeu ele que, embora a Constituição não disponha sobre a sanção do abandono do partido, esta estaria nela implícita, salvo motivo justo. E isto tanto para os eleitos segundo o sistema de representação proporcional deputados - como para os eleitos em eleição majoritária como senadores. ${ }^{2}$

Tal orientação já foi corroborada pelo Supremo Tribunal Federal quanto à questão da perda do mandato dos eleitos pelo sistema proporcional que tinham abandonado o partido pelo qual se haviam elegido. ${ }^{3}$ Posteriormente a isto, o Tribunal

${ }^{2}$ Sobre deputados que deixaram o partido pelo qual se tinham elegido TSE Consulta $\mathrm{n}^{\circ} 1.398$, Relator: Min. César Asfor Rocha. Sobre eleitos em eleição majoritária, TSE Consulta n ${ }^{\circ} 1.407$, Relator: Min Carlos Britto.

${ }^{3}$ Mandados de segurança MS 26.602, Rel.: Min. Eros Grau; MS 26.603, Rel. Min. Celso de Mello; MS 26.604, Min. Carmen Lúcia. 
Superior Eleitoral editou uma Resolução dispondo sobre o assunto. ${ }^{4}$ Quanto aos eleitos em votação majoritária os senadores e chefes do Executivo ainda não houve manifestação da Corte Suprema, mas se estima que siga a mesma orientação.

\section{C Controle da atuação dos Poderes}

9. O controle jurisdicional também se estende no Brasil ao campo da atuação política governamental, e tanto do Legislativo, quanto do Executivo. Não só ela é prevista para corrigir a ação destes Poderes, mas, outrossim, para ditá-la, impondo políticas públicas. E, num caso ao menos, é expressamente condição da atuação governamental.

\section{A) O CONDICIONAMENTO DA INTERVENÇÃO FEDERAL}

10. Este último caso, na verdade, é atualmente de pouco importância prática, mas significativo no seu contexto histórico e constitucional.

O Estado federal brasileiro prevê que a União intervenha nos Estados para determinadas finalidades de elevado interesse nacional, bem como para impor o respeito a vários princípios considerados essenciais à unidade do País - os chamados "princípios sensíveis". Este instrumento foi utilizado abusivamente durante a Primeira República (1891-1930), de modo que já na Constituição de 1934 se procurou impor-lhe condições isentas de faccionalismo político. Foi assim que, nessa Carta, pela primeira vez, se instituiu um crivo judicial prévio à sua decretação, isto quando seu fundamento fosse o descumprimento dos princípios sensíveis (art. $12, \S 2^{\circ}$ ). Com efeito, o texto previu fosse ela condicionada pela declaração da constitucionalidade da lei que a decretasse. Tal constitucionalidade importaria evidentemente na verificação da ocorrência dos pressupostos da intervenção, o que exigiria a apuração da inconstitucionalidade do ato estadual que a ensejava.

$\mathrm{Na}$ Constituição em vigor, o condicionamento persiste. Com fundamento em violação por ato estadual dos princípios sensíveis ou por recusa da execução de lei federal, poderá ser decretada a intervenção federal, mas apenas depois que o Supremo Tribunal Federal julgar procedente representação do Procurador-Geral da República, assim declarando a inconstitucionalidade ou a recusa (art. 34, III). Entretanto, bastará, nesta hipótese, decreto suspendendo o ato impugnado, "se essa medida bastar ao restabelecimento da normalidade". Na prática, é isto o que ocorre, sem maiores problemas nem contestações, o que exclui a intervenção federal propriamente dita.

${ }^{4}$ Resolução n ${ }^{\circ} 22.610$. 


\section{B) O CONTROLE DE CONSTITUCIONALIDADE}

11. Data da Primeira República o controle de constitucionalidade no Brasil, seguindo o dito modelo norte-americano. Ou seja, o controle, in concreto, incidenter tantum, que pode ser exercido por qualquer juiz, em qualquer pleito, mesmo ex officio, cabendo a última palavra na declaração da inconstitucionalidade ao Supremo Tribunal Federal por meio do recurso extraordinário.

Tal sistema continua presente no direito constitucional brasileiro, mas hoje coexiste com o controle abstrato, principal, em constante expansão. Como se sabe, a Reforma do Judiciário de 1965 (Emenda Constitucional n ${ }^{\circ}$ 16/1965 à Constituição de 1946) instituiu uma "representação contra inconstitucionalidade de lei ou ato de natureza normativa, federal ou estadual, encaminhada pelo Procurador-Geral da República", a ser processada e julgada pelo Supremo Tribunal Federal (CF 1946, art. 101, I, “k”). Isto se manteve na Constituição de 1967 e na Emenda n ${ }^{\circ} 1 / 69$, que a reescreveu. Veio essa representação a ser considerada uma ação direta de inconstitucionalidade e com este nome a prevê a Carta vigente (art. 101, I, "a"). Uma grande diferença, porém, se insinua entre a representação de 1965/1967 e ação direta de 1988: é a legitimidade ativa. Aquela somente competia ao Procurador-Geral da República, ao tempo de livre nomeação e de livre exoneração por parte do Presidente da República, esta tem a sua propositura aberta também a várias autoridades e órgãos políticos, bem como ao Conselho Federal da $\mathrm{OAB}$, a partido político com representação no Congresso Nacional e a confederação sindical ou entidade de classe de âmbito nacional (CF art. 103). Isto levou, na prática, a uma multiplicação de tais ações.

Acrescente-se que a Emenda Constitucional no 3/93 trouxe um novo meio de apreciação de constitucionalidade, a dita ação declaratória de constitucionalidade. Esta, cuja legitimidade ativa hoje é estendida a todos que a possuem para a ação direta de inconstitucionalidade, visa, como o nome indica, a declarar a constitucionalidade de um ato normativo federal, o que tem a significação prática de ensejar seja a questão subtraída ao controle incidenter tantum.

Enfim, a argüição de descumprimento de preceito fundamental decorrente da Constituição que previa, "na forma da lei" o art. 102, $\S 1^{\circ}$ da Constituição foi regulamentada em 1999 (Lei n ${ }^{\circ}$ 9.882). Nela, veio a ser previsto que o Supremo Tribunal Federal possa, em liminar, suspender o andamento de processos e os efeitos de decisões judiciais, até que delibere em tese sobre a questão jurídica em debate inclusive questão constitucional tendo a decisão do STF eficácia contra todos e efeito vinculante. Complemente-se que a argüição pode colher controvérsia constitucional sobre ato normativo, não só federal ou estadual, mas igualmente municipal. Ora, como os atos normativos do Poder local não podem ser alcançados pela ação direta de inconstitucionalidade, o texto opera uma extensão do controle que, por esse caminho, chega ao plano dos Municípios. 
12. Seguindo literalmente as palavras de Marshall, no caso Marbury v. Madison, uma corrente formalista quis, e quer negar, que o controle de constitucionalidade tenha naturalmente um viés político. Sem dúvida, ele se opera pelo discurso do direito e em face de norma definida pela Constituição, mas por sua significação e efeitos tem sempre uma conotação política. Esta, aliás, é implicitamente reconhecida em sistemas de Justiça constitucional em que órgãos políticos Legislativo e Executivo escolhem os membros da Corte constitucional, de composição temporária.

No direito brasileiro em vigor, essa conotação não pode ser mais ocultada. De fato, duas leis o indicam. São a Lei $n^{\circ}$ 9.868/99, que regula a ação direta de inconstitucionalidade e a ação declaratória de constitucionalidade, e a Lei ${ }^{\circ}$ 9.882/99 já referida que regula a argüição de preceito fundamental.

Estas duas Leis dispõem, aquela no art. 27 para a ação direta de inconstitucionalidade e para a declaratória de constitucionalidade, esta no art. 11 para a argüição de descumprimento de preceito fundamental, que a decisão que reconhecer a inconstitucionalidade, "tendo em vista razões de segurança jurídica ou de excepcional interesse social", poderá "restringir os efeitos daquela declaração ou decidir que ela só tenha eficácia a partir de seu trânsito em julgado ou de outro momento que venha a ser fixado", isto pela maioria de dois terços do Supremo Tribunal Federal.

A interpretação deste preceito mostra o abandono da tese da nulidade absoluta do ato inconstitucional, pois restringir os efeitos da declaração de inconstitucionalidade não é outra coisa senão ensejar que norma inconstitucional não seja anulada (o que importa em modificar a Constituição). E a fixação do termo a quo, tem a mesma significação conquanto temporariamente.

Ora, o caráter político de tal restrição, permanente ou temporária, é incontestável. Basta considerar que ela se pode dar, com fundamento na segurança jurídica, não só, mas também em razão de "excepcional interesse social", o que é uma apreciação subjetivamente aberta e política na sua substância. Com isto, o Supremo Tribunal Federal pode ir além da mera correção de atos inconstitucionais, assumindo um papel de construtor da Constituição. E, como as decisões no controle abstrato têm eficácia contra todos e efeito vinculante, tal construção não passará pelo crivo de outro órgão ou Poder.

13. Este último aspecto se acentua quando se considera que a Emenda Constitucional $n^{\circ}$ 45/2004 habilitou o Supremo Tribunal Federal a editar súmulas vinculantes, sempre pela maioria de dois terços de seus membros (CF art. 103-A). Com efeito, pode ele editar tais súmulas que terão efeito vinculante em relação a todos os órgãos do Poder Judiciário e à administração pública direta e indireta, a partir de sua jurisprudência, súmulas estas que terão por objetivo "a validade, a interpretação e a eficácia de normas determinadas". Serão elas, portanto, verdadeiras "leis" de interpretação da Constituição. 


\section{C) A CORReÇÃo de atos POlíticos E POLítico-Administrativos}

14. Acresça-se a isto que não prevalece no Brasil o princípio do judicial restraint a limitar a intervenção do Judiciário na órbita das questões políticas. Por força do art. $5^{\circ}, \mathrm{XXXV}$ da Constituição, não pode ser excluída da apreciação do Poder Judiciário "qualquer lesão ou ameaça a direito". Ora, com base nele, este Poder pode corrigir atos políticos, sejam de índole administrativa ou não.

Assim, o Supremo Tribunal Federal pode interferir, e tem interferido, no plano interna corporis do Legislativo, como comprovam suas decisões acerca de Comissões Parlamentares de Inquérito e Medidas Provisórias.

15. Igualmente, tem penetrado na seara do Executivo, exercendo um crivo sobre atos administrativos de execução de políticas governamentais. Este controle é provocado por diferentes remédios, seja por mandados de segurança, ou mandados de segurança coletivos, mas pode sê-lo por outras ações, como o por hábeas corpus, se for o caso.

Entretanto, merecem destaque dois instrumentos importantíssimos para a efetivação desse crivo: a ação popular e a ação civil pública.

A ação popular está presente no direito brasileiro desde a Constituição de 1934. Na atual, é ela prevista no capítulo sobre os direitos individuais e coletivos, especificamente no art. $5^{\circ}$, LXXIII da Constituição. Segundo este, qualquer cidadão pode propor tal ação para "anular ato lesivo ao patrimônio público ou de entidade de que o Estado participe, à moralidade administrativa, ao meio ambiente e ao patrimônio histórico e cultural".

A ela se ajunta a ação civil pública, criada em 1985, mas alargada no seu alcance pela Constituição vigente. Destina-se ela a proteger os interesses difusos da sociedade, nisto incluídos o meio ambiente, os direitos do consumidor, bens de valor estético, histórico, turístico e paisagístico. Pode ela ser proposta por associações civis, pessoas jurídicas estatais e para-estatais, mas também pelo Ministério Público. A competência deste é, aliás, definida na Constituição, como a de "promover o inquérito civil e a ação civil pública, para a proteção do patrimônio público e social, do meio ambiente e de outros interesses difusos e coletivos" (art. 129, III).

Fácil é imaginar a interferência que ensejam essas ações na condução dos negócios públicos, para corrigir vícios, ou para adequá-los a princípios de que é fértil a Constituição.

\section{D) A PROMOÇão de POlíticas públicas}

16. Deve-se acrescentar que os diferentes remédios constitucionais têm sido utilizados, não apenas para corrigir vícios, impondo princípios e regras, mas também para promover ações governamentais e mesmo políticas públicas. 
São numerosas as decisões judiciais que, mormente em ações civis públicas e em mandados de segurança coletivos,vem determinando que o Poder público execute determinadas políticas públicas, como criação de vagas nas escolas, melhoramentos em museus, reparo em prisões, etc.

Não raro essas decisões se propõem a efetivar direitos, como o direito à saúde determinando, por exemplo, que a alguém sejam oferecidos certos remédios ou disponibilizados certos tratamentos o direito à educação caso das vagas nas escolas, etc., isto por mandados de segurança individuais.

Esta orientação se arrima, por um lado, no já referido art. $5^{\circ}, \mathrm{XXXV}$ da Constituição; por outro, no art. $5^{\circ}, \S 1^{\circ}$, conforme o qual "as normas definidoras de direitos e garantias fundamentais têm aplicação imediata".

\section{E) O SUPLEMENTO DAS OMISSÕES}

17. Considere-se mais que a Constituição tem horror às omissões governamentais, por isso prevê remédios para colmatá-las.

Um deles é a ação de inconstitucionalidade por omissão (art. 103, § $2^{\circ}$ ). Em decorrência desta, o Supremo Tribunal Federal poderá declarar a ausência de medida necessária para a efetivação de comando constitucional, dando disto ciência ao Poder competente. Se omissão for de Poder, apenas dará disto ciência, mas, em se tratando de órgão administrativo, determinará que a edite em trinta dias.

Outro é o mandado de injunção, previsto no art. $5^{\circ}$, LXXI. Este dispõe tão somente: "Conceder-se-á mandado de injunção, sempre que a falta de norma regulamentadora torne inviável o exercício dos direitos e liberdades constitucionais e das prerrogativas inerentes à nacionalidade, à soberania e à cidadania". Assim, o preceito apenas enuncia a hipótese, mas é silente quanto ao mandamento. Isto fez com que a doutrina se dividisse a seu respeito, entendendo alguns que esse mandado daria ao Judiciário o poder de estabelecer as normas regulamentadoras, outros que não poderia ir mais além do que a ação de inconstitucionalidade por omissão e, portanto, conduziria apenas à verificação da lacuna e à ciência disto ao Poder competente. A jurisprudência do Supremo Tribunal Federal tomou de início posição cautelosa, mas veio a prever que, findo um certo prazo, o direito se exercitaria independentemente de norma regulamentadora, antes de assumir a posição de que, em face da omissão, o Judiciário definiria as normas a aplicar no caso debatido. Fê-lo, por exemplo, a propósito da regulamentação do direito de greve do servidor público. ${ }^{5}$

\footnotetext{
${ }^{5}$ Mandados de injunção MI 670, Rel. para o acórdão, Min. Gilmar Mendes; MI 708, Rel.: Min. Gilmar Mendes; MI 712, Rel.: Min. Eros Grau.
} 
Nota-se, destarte, que o Judiciário abandonou a posição tradicional de apenas corrigir as violações à Carta Magna e à lei, para assumir um papel positivo na construção do ordenamento e na concretização da Constituição, colmatando lacunas e omissões.

\section{F) A Abertura pelos princípios}

18. Este papel do Judiciário não é mero fruto de um ativismo de seus membros, embora este não deixe de existir, mas é conseqüência da Constituição. Esta o enseja, não apenas pelos instrumentos acima apontados que consagra, mas também por sua índole aberta. É ela uma Constituição que impõe, além de regras, também princípios, e são muitos os princípios que o texto expressamente manda observar e que, portanto, podem e devem ser aplicados pelos juízos e tribunais.

Veja-se, por exemplo, que o art. 37, caput da Constituição comanda que "a administração pública direta e indireta da União, dos Estados, do Distrito Federal e dos Municípios" deva "obedecer aos princípios de legalidade, impessoalidade, moralidade, publicidade e eficiência". Aí, se torna claro, por exemplo, que a legalidade é apenas um dos princípios regentes da administração e que pode ser posto de lado se conflitar com a moralidade, ou com a eficiência.

Isto leva não raro o Judiciário a substituir sua apreciação do mérito de um ato administrativo em nome, por exemplo, da eficiência ao juízo do Poder Executivo. Igualmente, claro está que a densificação destes princípios dá ao Judiciário um amplo espaço de construção normativa, em concorrência com os dois outros Poderes.

Tudo isto relativiza a separação dos Poderes, sem embargo de a Lei Magna considerá-la "cláusula pétrea" (art. 60, § $4^{\circ}$, III).

\section{O JUDICIÁRIO NO SISTEMA CONSTITUCIONAL BRASILEIRO}

19. O panorama registrado corrobora a tese apontada logo nas primeiras linhas deste trabalho, segundo a qual o Judiciário exerce um amplo controle sobre a atividade política.

$\mathrm{O}$ termo controle parece ser adequado para o registro exatamente porque ele tem duas faces, a de fiscalização e a de comando. O Judiciário brasileiro, e, particularmente na sua cúpula, o Supremo Tribunal Federal, tem um amplo poder de fiscalização corretiva da atividade política. Tem mais, porém. Possui um poder de comando político, na medida em que pode participar da construção do ordenamento jurídico, não só infraconstitucional, mas também constitucional, em concorrência com o Legislativo, e determinar ações administrativas, inclusive políticas públicas, em concorrência com o Executivo. Assim, atua "negativamente", corrigindo infrações à Constituição e à lei, e, "positivamente", desempenhando um papel normativo que se eleva a um verdadeiro poder constituinte derivado. 
Ademais, é árbitro do processo eleitoral e partidário, conseqüentemente desempenhando um papel crucial no funcionamento das instituições democráticas.

Tudo isto traduz, numa ampla medida, uma judicialização da política. E obriga ao reconhecimento do Judiciário como um Poder político (no melhor sentido do termo). Não pode isto ser ignorado na interpretação do sistema brasileiro de "separação" dos poderes.

20. Tal judicialização suscita uma preocupação. Não terá ela a contrapartida de uma politização (no mau sentido) do Judiciário?

O risco é grande.

Os meios de comunicação de de massa já parecem encarar o Judiciário, mormente o Supremo Tribuanl Federal, como um ente politizado, cujas posições são apreciadas como favorecendo a correntes políticas, o mais das vezes numa bipolarização Governo v. Oposição.

Isto, sem dúvida, é favorecido pelo sistema de escolha dos Ministros do Supremo Tribunal Federal que, embora seja feita em observância a elevados critérios de seleção, enseja a suspeição de intuitos político-partidários. E acresce a esta suspeita o fato de serem vitalícios os Ministros, de modo que partido poderia, em tese, assegurar a maioria na Corte Suprema por longo período.

Observe-se, ademais, que a utilização de instrumentos como a ação civil pública e a ação popular têm servido a propósitos que nem sempre coincidem com o zelo pelo direito e pela justiça. Indubitavelmente, a elite dos doutores se tem servido dessa judicialização para procurar impor seus elevados ideais ou prioridades. Nisto, inspiram-se orientações como a do neoconstitucionalismo ou a da "constitucionalização" do direito privado.

Existe, ainda, um ativismo da parte de certos magistrados que pretendem batalhar pela democracia e pelo social. Entretanto, não se pode dizer que seja este fator subjetivo o prevalecente no posicionamento do Judiciário brasileiro como Poder político de controle. Há, como se assinalou, suficientes elementos objetivos para ditá-lo.

21. A judicialização, por outro lado, provoca uma meditação sobre a natureza do regime de governo que funciona no Brasil. Sim, porque, se a democracia implica que "todo o poder emana do povo que o exerce por meio de representantes eleitos ou diretamente", conforme está no art. $1^{\circ}$, parágrafo único da Constituição brasileira, o Poder Judiciário não emana do povo, nem é integrado por representantes eleitos. Estaremos diante de um regime misto? Com um elemento monárquico, o Executivo presidencial, um elemento representativo, o Legislativo, ambos, sim, de fonte, democrática, e um Judiciário aristocrático (no melhor sentido do qualificativo)? 
A colocação certamente é polêmica. Trata-se, contudo, de uma indagação objetiva, científica. Não envolve qualquer parti pris, seja para denegrir a atuação política do Judiciário, seja para enfraquecer a democracia. Muito menos visa ela a propor a eleição dos juízes que certamente provocaria a prevalência da demagogia sobre a justiça.

É certo, porém, que tal questionamento merece ser examinado, pois dele depende um juízo não apenas sobre os rumos tomados, e sua eventual correção, como, outrossim, sobre pontos controversos, como a instituição, no Brasil, de uma Justiça constitucional independente do Judiciário.

São questões a serem enfrentadas pelos mais sábios.

SP, janeiro 2008. 